\title{
Fat Graft Myringoplasty- Day Care Procedure: Role in Small Central Perforations
}

\author{
Nanda MS', Kaur $M^{2}$, Luthra $D^{3}$ \\ ${ }^{1}$ Dr Manpreet Singh Nanda, Assistant Professor, Department of Otolaryngology - Head and Neck Surgery, Maharishi \\ Markandeshwar Medical College \& Hospital, Kumarahatti, Solan, Himachal Pradesh, India, ${ }^{2}$ Dr Mandeep Kaur, Assistant \\ Professor, Department of Anaesthesia, Maharishi Markandeshwar Medical College \& Hospital, Kumarahatti, Solan , \\ Himachal Pradesh , India, ${ }^{3}$ Dr Dinesh Luthra, Professor \& Head, Department of Otolaryngology - Head and Neck \\ Surgery, Chintpurni Medical College \& Hospital, Bungal, Pathankot, Punjab, India
}

Address for correspondence: Dr Manpreet Singh Nanda, Email: u_tell_me_80@yahoo.co.in

\begin{abstract}
Introduction: Day care surgery is the need of hour in the field of otology. Temporalis fascia is the most common material used for closure of tympanic membrane perforation. But it is a lengthy procedure requiring general anaesthesia (GA) or longer sedation, extensive middle ear manipulation and a longer recovery post operatively. Fat is said to have angiogenetic properties. The aim of this study is to evaluate the usefulness of adipose tissue fat for closure of dry small perforations of tympanic membrane as a day care procedure. Materials and Methods: 40 patients with small central dry tympanic membrane perforations were taken up for surgery under sedation using fat graft from ear lobule for closure of perforations. The results were evaluated inta operatively, immediate post operatively and at $1^{\text {st }}, 4^{\text {th }}, 8^{\text {th }}$ and $12^{\text {th }}$ monthly post operative visit for uptake of graft, hearing improvement and complications of the procedure if any. Results: The results showed that the graft uptake success rate was high as good as traditional myringoplasty using temporalis fascia. The procedure was minimally invasive, requiring little sedation, taking much less time, cost effective where both ears can be operated in the same sitting and the patients can be discharged on the same day with no major complications. There was considerable hearing improvement noted in the patients in the study. Conclusion: So it can be concluded that fat graft myringoplasty is an effective method for closure of small central dry tympanic membrane perforations.
\end{abstract}

Keywords: Chronic Otitis Media, Fat Graft Myringoplasty, Myringoplasty, Middle ear perforation

\section{Introduction}

Myringoplasty is the most common surgery performed in otology due to high incidence of tympanic membrane perforation. A variety of graft matierials like fascia, cartilage, perichondrium and fat are documented in literature for closure of perforation [1]. Temporalis fascia is the most common graft material used for this surgery. But temporalis fascia when used requires extensive middle ear manipulation and general anaesthesia or longer sedation, a lengthy procedure which is unacceptable in the era of day care surgery especially for small central dry perforation.

Fat is an active material which is said to have angiogenetic properties [2]. It has been a accepted material for closure of small tympanic membrane

Manuscript received: $22^{\text {nd }}$ Dec 2014

Reviewed: $6^{\text {th }}$ Jan 2015

Author Corrected: 14 $4^{\text {th }}$ Jan 2015

Accepted for Publication: $22^{\text {th }}$ Jan 2015 perforations in literature [3]. Various studies done by Ringenberg, Liew, Hagemann and Saliba have shown positive results with fat graft myringoplasty. A study by Benson et al has shown the success rate and effectiveness of day care procedure [4]. But this procedure of fat graft myringoplasty has been underused [5]. This study aims to evaluate the usefulness of adipose tissue fat for closure of dry small perforations of tympanic membrane as a day care procedure, to evaluate its advantages and drawbacks and complications if any.

\section{Materials and Methods}

This study was a prospective study conducted in department of ENT of our medical college and hospital for a period of 18 months from March 2011 to August 2012. The follow up was done for a period of 1 year post operatively. 40 patients with small central tympanic
Available online at: www.ijmrr.in $79 \mid \mathrm{P}$ a g e 
membrane perforations (unilateral or bilateral), aged between 18 to 60 years were enrolled in the study after obtaining written consent from the patients. The approval of local ethics committee was taken. The criteria for selection of patients are enlisted in Table 1 .

Table 1: Selection criteria for patients

\begin{tabular}{|l|l|}
\hline S. No & Selection Criteria \\
\hline 1 & Central perforation confined to less than $25 \%$ area of pars tensa \\
\hline 2 & Air bone gap less than 45 decibels \\
\hline 3 & Perforation persistent for atleast 6 months \\
\hline 4 & No active ear discharge for atleast 3 months \\
\hline 5 & No history of previous ear surgery \\
\hline 6 & No evidence of cholesteatoma \\
\hline 7 & No Eustachian tube dysfunction \\
\hline
\end{tabular}

All the patients were operated by the ENT surgeons performing the study and the sedation was given by the anaesthesist performing the study. The surgical procedure was done under local anesthesia with sedation with dexmedetomidine. Out of 40 patients, 30 patients had unilateral perforation, whereas 10 patients had bilateral perforation. In case of bilateral perforation both ears were operated in the same sitting. In total 50 ears were operated in this study (Table 2).

Table 2: Total patients and ears operated

\begin{tabular}{|l|l|l|}
\hline Perforation & Total patients & Total ears operated \\
\hline Unilateral & 30 & 30 \\
\hline Bilateral & 10 & 20 \\
\hline & $\mathbf{4 0}$ & $\mathbf{5 0}$ \\
\hline
\end{tabular}

All the patients had underwent examination under microscope, complete hearing assessment, radiological assessment and Eustachian tube function tests before the surgical procedure.

\section{Surgical procedure}

"After shifting the patient to the operation theatre, sedation was given using dexmedetomidine. $2 \%$ lignocaine with 1 : 100,000 adrenaline infiltration was given in the ear canal and on the ear lobule. A $5 \mathrm{~mm}$ incision is made in the medial part of ear lobule and fat tissue is harvested double the size of the tympanic membrane perforation. The incision is sutured with silk. The edges of the perforation are freshened using sickle knife. Gel foam is placed in the middle ear. The piece of harvested fat position as a graft over the perforation in a hour glass fashion so that a part of it is above the perforation. Gel foam placed over it and on the sides. No dressing needed. Patient shifted to the post operative ward."

The patients were discharged on the same day after 3 to 4 hours of observation with the instructions to keep the ear dry. The follow up of the patients was done after 1 month when the remaining gel foam was cleared under microscope. The uptake of graft and hearing improvement was assessed after 4 months post operatively. Subsequent follow up was done after 8 and 12 months post operatively.

The patients were assessed for the following points -

- Successful uptake of fat graft

- Hearing improvement in the patients

- Time taken for surgery and recovery

- Complications of the procedure if any

- Patient and surgeon satisfaction 


\section{Results}

40 patients with small central tympanic membrane perforation who gave consent were enrolled in this study. All the patients had undergone fat graft myringoplasty under sedation for closure of perforation. Data was collected on all patients. All the patients were in the age group 18 to 60 years. The majority of patients were in the younger and middle age groups (Table 3). There was a slight male predominance among the patients in our study (Table 3).

Table 3: Age and Sex wise distribution

\begin{tabular}{|l|l|l|l|}
\hline Age Group & Male & Female & Total \\
\hline $18-30$ & 11 & 9 & 20 \\
\hline $31-50$ & 9 & 8 & 17 \\
\hline $51-60$ & 2 & 1 & 3 \\
\hline Total & $\mathbf{2 2}$ & $\mathbf{1 8}$ & $\mathbf{4 0}$ \\
\hline
\end{tabular}

Regarding the cause of perforation the majority 24 patients $(60 \%)$ had history of infection chronic suppurative otitis media whereas remaining 16 patients $(40 \%)$ had traumatic etiology (Fig 1).

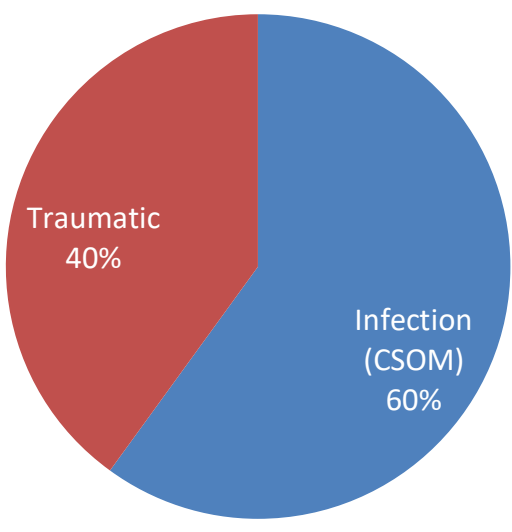

Fig 1: Etiology of Perforation

Regarding the intraoperative findings, the procedure was simple, easy to perform, average surgical operating time was 20 minutes, and cost of procedure was very minimal as compared to conventional myringoplasty with no major complications during procedure (Table 4). All the patients were discharged on the same day and there was no need of any dressing for any patient (Table 4).

\section{Table 4: Operative findings}

\begin{tabular}{|l|l|l|l|}
\hline S. No & Finding & Result & Inference \\
\hline 1 & Total operating time (average) & 31 minutes & Done under sedation. No need for GA \\
\hline 2 & Surgical operating time (average) & 20 minutes & Short and easy procedure \\
\hline 3 & Intra operative complications & 0 patients $(0 \%)$ & Safe procedure \\
\hline 4 & Total operating cost (average) & Rs 1500 & Cost effective \\
\hline 5 & Post operative dressing & 0 patients $(0 \%)$ & Minimal invasive. No need for dressing \\
\hline 6 & Discharge of patients & $\begin{array}{l}\text { Same day, after 3 to } 4 \\
\text { hours post operatively }\end{array}$ & Faster recovery \\
\hline
\end{tabular}

Note - Total operating time was the time that the patient stayed in the operation theatre. Surgical operating time was the time from starting of the local infiltration till the end of surgical procedure. 
The satisfaction of the patient and surgeon was calculated according to LIKERT scale [6]. Patient satisfaction was enquired 3 to 4 hours after surgery at the time of discharge of patient from hospital. The results showed greater surgeon and patient satisfaction with fat graft myringoplasty (Table 5). 38 patients (95\%) were satisfied (most of them extremely satisfied) after the surgery. Only 2 patients were undecided about their satisfaction in the study. Regarding surgeon satisfaction, there was complete (100\%) surgeon satisfaction in all the 40 cases operated using fat graft. In most of these cases the surgeon was extremely satisfied (Table 5).

Table 5: Patient and Surgeon satisfaction results

\begin{tabular}{|l|l|l|}
\hline Result & Patient Satisfaction (Total patients - 40) & Surgeon Satisfaction (Total cases - 40) \\
\hline Extremely Unsatisfied & 0 patients $(0 \%)$ & 0 cases $(0 \%)$ \\
\hline Unsatisfied & 0 patients $(0 \%)$ & 0 cases $(0 \%)$ \\
\hline Undecided & 2 patients $(5 \%)$ & 0 cases $(0 \%)$ \\
\hline Satisfied & 3 patients $(7.5 \%)$ & 2 cases $(5 \%)$ \\
\hline Extremely Satisfied & 35 patients $(87.5 \%)$ & 38 cases $(95 \%)$ \\
\hline
\end{tabular}

The uptake of graft and hearing improvement was assessed after 4 months post operatively. Regarding uptake of fat graft, it was successful in 45 of 50 operated ears (90\%). In 3 ears $(6 \%)$ there was complete graft failure due to infection and in 2 ears (4\%) there was residual perforation (Fig 2).

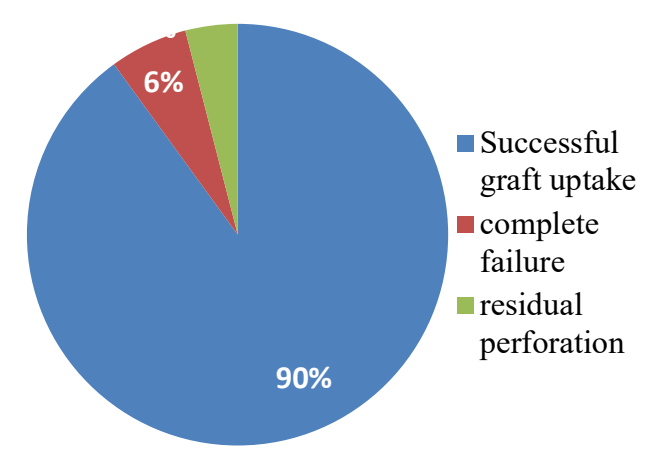

Fig 2: Fat graft uptake results

Post operative hearing improvement was evaluated by finding out if there was reduction in mean air bone gap in the patients. The mean air bone gap was calculated as the average of air bone gap at $500 \mathrm{~Hz}, 1000 \mathrm{~Hz}, 2000$ $\mathrm{Hz}$ and $4000 \mathrm{~Hz}$ frequencies. Our results showed there was reduction in mean air bone gap in 38 out of 40 patients $(95 \%)$. One patients with bilateral perforation and one with unilateral perforation who had complete failure of graft uptake due to infection didn't show any hearing improvement (Fig 3).

The same success results both for graft uptake and hearing improvement were seen after 8 months and 12 months post operatively.

\section{Discussion}

International Journal of Medical Research and Review

\section{Hearing improvement}

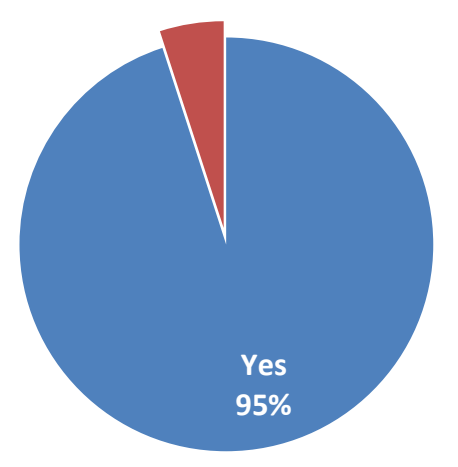

Fig 3: Hearing evaluation results

The efficacy of fat graft myringoplasty for small central perforations was evaluated in this study. The aim of this study was to evaluate the usefulness of adipose tissue fat for closure of dry small perforations of tympanic membrane as a day care procedure, to evaluate its advantages and drawbacks and complications if any

Tympanic membrane perforations are the most common ear disorders. The most common etiology for the same is trauma, infection or post tympanostomy tube extraction [7]. In our study also we found infection and trauma to be the most common etiology (Fig 1). Variety of graft materials like temporalis fascia, tragal cartilage, fat, perichondrium can be used for closure of these perforation. Ringenberg described fat plug myringoplasty in 1962 with a success rate of 87\% [8]. 
Various studies have shown success rate between $76 \%$ to $92 \%$ for small central perforations. Our study also had a graft uptake success rate of $90 \%$ (Fig 2). These results are comparable with success rate of overlay technique and underlay technique using temporalis fascia.

Fat can be harvested from abdomen, buttock or ear lobule. Ear lobule is the simpler method with same operating area and invisible marginal scar. So it is the ideal area for harvesting of fat graft. Fat tissue provides the basic requirement for grafting of tympanic membrane with its own favourable characterstics [9]. Fat is an active material containing angiogenic and survival factors like monobutyrin, prostaglandins, interleukins, cytokines and tumour necrosis factor which restores and repairs the fibrous layer and promotes revascularization which is essential for success of free flap [10]. According to studies by Liew et al and Hagemann air bone gap improvement was seen in 11 out of 15 patients and 21 out of 44 patients respectively $[11,12]$. Similarly in our study reduction in air bone gap was noticed in 38 out of 40 patients (Fig 3).

Fat graft myringoplasty is said to be a short, simple, minimally invasive and cost effective technique [13]. Similar results were obtained in our study with this procedure requiring less operating time, being cost effective with no need for post operative dressing and no major intra operative complications and the patient was discharged on the same day (Table 4). Bilateral myringoplasty can be performed in the same sitting (Table 2). The results are satisfactory for both patient and surgeon (Table 5).

\section{Conclusion}

Fat graft myringoplasty is a safe and effective technique for closure of small central tympanic membrane perforations. The advantages of this technique are

- Simple technique with graft taken from same surgical field.

- No need for general anaesthesia, need minimal sedation.

- Less operating time.

- Day care procedure.

- Minimally invasive with no major intra operative complications.

- Faster recovery with no need for post operative dressing.

- Cost effective.

- Bilateral perforations can be grafted using fat graft in the same sitting.

International Journal of Medical Research and Review
- Excellent results for both graft uptake and hearing improvement, at par with temporalis fascia graft.

The results of the procedure are highly satisfactory for both patient and surgeon. So we can conclude that adipose tissue fat from ear lobule is an excellent graft material for closure of dry small perforations of tympanic membrane as a day care procedure and can be a preferred method of choice over temporalis fascia. There is scope of further studies along this line of management.

\section{Acknowledgments}

We would like to thank our institute for its support and the patients for cooperating with the study protocol.

Funding - NIL

Permission from IRB - Yes

Conflicts of interest - The authors report no conflicts of interest

\section{References}

1. Ayache S, Braccini F, Facon F, Thomassin JM. Adipose graft: an original option in myringoplasty. Otol Neurotol. 2003Mar;24(2):158-64.

2. Nishimura T, Hashimoto H, Nakanishi I, Furukawa M. Microvascular angiogenesis and apoptosis in the survival of free fat grafts. Laryngoscope. 2000 Aug; 110(8):1333-8.

3. Kim DK, Park SN, Yeo SW, et al. Clinical efficacy of fat graft myringoplasty for perforations of different sizes and locations. Acta Otolaryngol. 2011 Jan;131(1):22-6. doi: 10.3109/00016489.2010.499881. Epub 2010 Aug 24.

4. Benson Mitchell R, Gardiner Q, Kenyon GS. Day stay myringoplasty. J Laryngol Otol. 1996 May;110(5):421-4.

5. Ozgursoy OB, Yorulmaz I. Fat graft myringoplasty: a cost-effective but underused procedure. J Laryngol Otol. 2005 Apr;119(4):277-9.

6. Likert, Renesis. A Technique for the Measurement of Attitudes. Archives of physiology 1932;140: 1-55.
Available online at: $\underline{\text { www.ijmrr.in }} 83$ | P a g e 
7. Saliba I. Hyaluronic acid fat graft myringoplasty: how we do it. Clin Otolaryngol. 2008 Dec;33(6):610-4. doi: 10.1111/j.1749-4486.2008.01823.x..

8. Ringenberg JC. Fat graft tympanoplasty. Laryngoscope. 1962 Feb;72:188-92.

9. Boyce RG, Nuss DW, Kluka EA. The use of autogenous fat, fascia, and nonvascularized muscle grafts in the head and neck. Otolaryngol Clin North Am. 1994 Feb;27(1):39-68.

10. Zuk PA, Zhu M, Ashjian PV, et al. Human adipose tissue is a source of multipotent stem cells. Mol Biol Cell. 2002 Dec;13(12):4279-95.
11. Liew L, Daudia A, Narula AA. Synchronous fat plug myringoplasty and tympanostomy tube removal in the management of refractory otorrhoea in younger patients. Int J Pediatr Otorhinolaryngol. 2002; 66(3): 291-96.

12. Hagemann M. Hausler R. Tympanoplasy with adipose tissue. Laryngorhinootologie. 2003 Jun;82(6):393-6.

13. Chalishazar U. Fat plug myringoplasty. Indian J Otolaryngol Head Neck Surg. 2005 Jan;57(1):43-4. doi: 10.1007/BF02907626.

\section{How to cite this article?}

Nanda MS, Kaur M, Luthra D. Fat Graft Myringoplasty- Day Care Procedure: Role in Small Central Perforations . Int J Med Res Rev 2015;3(1):79-84. doi: 10.17511/ijmrr.2015.i1.13 